\title{
TI.124.1
}

\section{Internet2 Trust and Identity Accomplishments}

- PDF: 2018 Trust and Identity Accomplishments.pdf

- Text: 2018 Trust and Identity Accomplishments.txt

\section{More Information}

\begin{tabular}{|c|c|}
\hline Repository ID & TI.124.1 \\
\hline Persistent URL & http://doi.org/10.26869/TI.124.1 \\
\hline Title & 2018 Internet2 Trust and Identity Accomplishments \\
\hline Authors & $\begin{array}{l}\text { Dean Woodbeck iD https://orcid.org/0000-0002-0996-1719 } \\
\text { Ann West iD https://orcid.org/0000-0002-8215-4913 } \\
\text { Kevin Morooney iD/ https://orcid.org/0000-0001-9058-3921 }\end{array}$ \\
\hline Sponsor & Vice President, Trust and Identity and NET+ \\
\hline \multicolumn{2}{|l|}{ Review } \\
\hline Status & Preserve \\
\hline Publish Date & March 28, 2019 \\
\hline DOI & $10.26869 / \mathrm{TI} .124 .1$ \\
\hline \multicolumn{2}{|l|}{ Signature } \\
\hline Deprecated & No \\
\hline \multicolumn{2}{|l|}{ Future Review } \\
\hline \multicolumn{2}{|l|}{ Supersedes } \\
\hline Format & PDF, Text \\
\hline \multicolumn{2}{|l|}{ Related Docs } \\
\hline Development Location & 2018 Trust and Identity Accomplishments.docx \\
\hline IP Framework & CC BY 4.0 \\
\hline Subject Tags & service \\
\hline Notes & \\
\hline
\end{tabular}

